\title{
Una mirada a Goya: los desastres de la guerra
}

\author{
Juana María Balsalobre García*
}

\begin{abstract}
RESUMEN
En primer lugar quiero señalar que la idea de este trabajo tiene en su base la preparación para participar con una conferencia en uno de los Seminarios de Verano, organizados por el Centro

Asociado a la UNED de Elche, cuyo director iba a ser el profesor Dr. $D$. Ángel Martínez de Velasco Farinós. Aquí se pretende reescribir aquel texto como testimonio ${ }^{1}$ e igualmente como visual histórica.

La grave situación politico-social determinada por la Guerra de la Independencia ${ }^{2}$ y las actuaciones del ejército invasor, marcaron, desde su inicio al pueblo, que lo sufrió. Son las fuentes documentales escritas las que aportan el conocimiento de los hechos pero también las fuentes gráficas $y$ entre ellas, tienen un
\end{abstract}

\section{ABSTRACT}

First of all I would like to point out that the base of this work is on the preparation to take part with a conference in one of the summer courses organized by the CENTRO ASOCIADO UNED, ELCHE, whose director was going to be the professor Dr. D. Ángel Martínez de Velasco Farinós. The aim here is to rewrite that text as a testimony as well as, as an historical view.

The gravity of the social-political situation caused by the independence war and the acts of the invading army, had a great influence on the common people who suffered them. The knowledge of the facts is mainly provided by the documentary written sources, but also by the graphic sources among which has a great

* Profesor-tutor del Centro Asociado a la UNED de Elche-Alcoy.

1 En memoria de un gran y especial ser humano, el profesor Ángel Martínez de Velasco Farinós, porque siempre estaba ahí y su buen hacer sigue presente.

2 Martínez de Velasco Farinós, Ángel; Sánchez Mantero, Rafael y Montero, Feliciano, Manual de Historia de España. Siglo XIX. Madrid, Historia 16, 1990. 
indudable interés, los llamados

Desastres de la Guerra. Obra del genial Francisco de Goya y Lucientes, que nació (1746) en el pueblo aragonés de Fuendetodos y murió a los 82 años (1828) en la ciudad francesa de Burdeos. interest the called "Desastres de la Guerra (War disasters)", Masterpiece of the genius artist Francisco de Goya $y$ Lucientes, born in 1746 in the aragonese town of Fuendetodos and dead at 82 years old in the French city of Bordeaux.

\section{UNA MIRADA A LA BIOGRAFIA DE GOYA}

Tanto la relevancia del pintor, la maestría de su obra y el contexto histórico, han sido objeto de especialistas y estudiosos que los han analizado dentro de tales realidades. Goya, no solamente las vivió y las sufrió, sino que también las superó al trasladarlas como imágenes pictóricas, que hablan por sí solas. Aunque a los 46 años (1792) se quedó sordo y su mundo cambió, la historia de la pintura lo ganó, de forma parecida a su coetáneo Beethoven (Bonn 1770-Viena 1827) pues actuaron de enlaces con la tradición y la superaron.

La fuerza creadora en Francisco de Goya ${ }^{3}$ es tan sustantiva y su personalidad tan significativa ${ }^{4}$, que, únicamente y por una cuestión sin-

3 Además de la destacada y numerosa bibliografía, hay que referirse a una de las aportaciones vertidas en internet con el título de INFOGOYA 96, es como se señala iniciativa de la Universidad de Zaragoza y ha sido patrocinada por la Institución Fernando el Católico de la Diputación de Zaragoza. Y entre otros soportes bibliográficos tenemos Videos: ChamorRo, Eduardo, y BETANCOR, Antonio: "El costumbrismo goyesco". Madrid, Ministerio de Cultura, 1990. 1videocasete (BETA). Duración: 30 minutos. Fernandez Santos, Jesús: «Goya». Madrid, Ministerio de Educación y Ciencia, 1972. 1 videocasete (VHS). Duración: 20 minutos. GALLEGo, Julián: «Los grabados de Goya. Pablo Gargallo escuitor. Zuloaga en la pintura española". Colegio Libre de Eméritos, 1992.1 videocasete (VHS). Duración: 120 minutos. Hulcl, Fernando; FERnÁndez, Miguel Ángel: «Goya, el capricho y la invención». MQ Producciones. Visual, 1993. 1 videocasete (VHS). Duración: 45 minutos. Pontón, Eugenio; Chamorro, Eduardo; Bernaldo de Quirós, Altredo; Morán Robles, María Teresa, y PARAmo, José Antonio: “Goya». TVE SA, 1989. 1 videocasete (VHS). Duración: 30 minutos.

4 La historiografía señala que el primer estudio sobre Goya se debe a Valentín Carderera y Solano, (1796-1880), pintor y coleccionista de obras de arte, que, además de la Biografía de Don Francisco de Goya, pintor, que se publicó en la revista El Artista en 1835, contribuyó en el siglo $x \mid x$, al nacimiento y al desarrollo de nuestra Historia del Arte. Más recientemente hay que referirse por ejemplo a los estudios de Valeriano Bozal Imagen de Goya (1983), analiza los cartones y la representación de lo popular, la colección de los Caprichos, los Desastres, los Disparates y las pinturas negras. El estudio plantea las reflexiones acerca de las ideas de Goya cuando hizo sus grabados. BozAL, Valeriano: "Pinturas negras de Goya». Madrid, 1997. «Goya. Entre Neoclasicismo y Romanticismo». Madrid, Historia 16, (s.a.). (Historia del Arte, 38). Imagen de Goya. Barcelona, Editorial Lumen, 1983. Goya y el gusto moderno. Madrid, Alianza Editorial, 1994. Del mismo año hay que señalar la obra Goya y el gusto moderno por Alianza Editorial y también otra publicación del año 1996 con el estudio llevado a cabo por José Gudiol Goya de 
tética se pueden establecer dos vertientes, dos líneas, una determinada por la pintura de encargo, y otra más analítica. Aquella corresponde, por ejemplo, a su faceta de pintor de cartones para la Real Fábrica de tapices, donde recrea escenarios y personajes del pueblo, a la que se puede añadir, entre otras muchas, su faceta de retratista de la nobleza, de los ilustrados e igualmente, por ser el pintor de Cámara de Carlos III (1786), de Carlos IV, (1789), y, obligado por las circunstancias políticas, a sus 63 años, a jurar fidelidad, la víspera de nochebuena del año 1809 , al rey intruso José I Bonaparte y, una vez acabada la Guerra de la Independencia, en 1814 a retratar a Fernando VII en un campamento (Museo del Prado) y al mismo rey con manto real (Museo de Zaragoza), con la vuelta al absolutismo. A los intentos de implantar una monarquía constitucional ${ }^{5}$ se sucedería la década más negra, la ominosa, de 18231833, con la que acabaría el reinado de Fernando VII. La otra línea, corresponde por ejemplo a la serie denominada por el pintor Los Desastres de la Guerra, donde muestra una visión personal y critica de la

\footnotetext{
las distintas etapas artística $(1746-1774,1774-1785,1786-1792,1792-1806$ y 1807-1828) y la evolución artística del pintor. Asimismo es obligado citar a Jesusa Vega González, y también, respecto a la Historia del grabado a Juan Carrete Parrondo (Academia de San Fernando). Son muchas las perspectivas de los estudios publicados y precisamente por ello no se pueden citar, por ejemplo, recientemente ha salido a la luz, una relevante obra, en dos volúmenes, el primero lieva por título Imágenes contra la guerra: Coincidencias y discrepancias en torno a los Desastres. El proceso de creación gráfica: dibujos, pruebas de estado y Álbum de Ceán. Repertorio bibliográfico (336 pp, 202 ilustraciones), y el primer autor es, el comisario de las exposiciones, que seguidamente se comenta, José Manuel Matilla y Javier Blas, también del segundo en el que colabora, Isla Aguilar, la comisaria adjunta, que trata de Desastre a Desastre. Elenco de referencias críticas. La difusión de las imágenes: láminas de cobre y estampas de la primera edición (256 pp, con 164 ilustraciones). Se debe señalar que Goya y su obra ha sido objeto de diferentes EXPOSICIONES, como la organizada, últimamente, con la colaboración de la Calcografía Nacional, la Real Academia de Bellas Artes de San Fernando y la Biblioteca Nacional, patrocinada por la fundación Winterthur. Pensada en tres partes, la primera con el título de El proceso creativo: del dibujo al grabado (18 diciembre de 2000 al 11 marzo de 2001), la segunda, El horror de la sinrazón, (19 marzo de 2001 al 17 junio de 2001), la tercera, Los caprichos enfáticos, (25 junio de 2001 al 17 septiembre de 2001), Producidas y realizadas por el Museo Nacional del Prado.

5 «Dada la importancia que para el desarrollo posterior del Trienio liberal tuvo la etapa de transición comprendida entre el decreto de juramento de la Constitución por el Rey el 7 de marzo de 1820 y la reunión de las Cortes ordinarias el 9 de julio del mismo año, sorprende la escasa atención que la historiografía ha prestado al tema. Este hecho lleva a pensar que, aparte del cúmulo de decretos restableciendo el orden constitucional, se desconoce la mecánica interna del gobierno en este periodo y, con ello, el papel que la Junta Provisional, verdadero eje de la transición política, jugó en los primeros pasos dados por los liberales para llevar a la práctica no sólo la Constitución de 1812, sino toda una concepción de vida distinta a la del régimen hasta entonces vigente" en BULDAIN JACA, Blanca Esther: Regimen político y preparación de Cortes en 1820. Madrid, publicaciones del Congreso de los Diputados. Dirección de Estudios y Documentación de la Secretaría General, 1988, pág. 11.
} 
realidad de la época ${ }^{6}$, bajo los diferentes aspectos del dramatismo del enfrentamiento bélico.

Entre las dos vertientes, y por lo que se expone a continuación, se puede establecer el comentario a dos lienzos, sobre la Guerra de la Independencia, muy conocidos el Dos de Mayo de 1808 o Carga de los mamelucos y el Tres de Mayo o Los fusilamientos de la Moncloa. El pintor ha sido mucho más que un cronista gráfico de su época puesto que toma partido, y como expresa el profesor García Melero ya no se idealiza e identifica al héroe, los personajes, de las dos escenas, son anónimos y, no se enfrentan a su destino trágico e injusto de una forma heroica, sino mostrando todo su espantoso horror ante la propia muerte y la inutilidad de su sacrificio. "Goya, que en los primeros tiempos del retorno de Fernando VII a España retrató al general Palafox a caballo (Museo del Prado), solicitó ayuda al Consejo de Regencia, instaurado en Madrid, para realizar cuadros de historia que reflejaran el heroísmo de los patriotas ante las tropas francesas invasoras. Tal es el origen de los dos cuadros de exaltación patriótica que reproducen los acontecimientos bélicos acaecidos en la Villa y Corte en los días 2 y 3 de mayo de 1808. El mismo tema había sido ya representado en los grabados del año 1813 de López Enguídanos, y en los de Ribelles y Alejo Blanco de 1814, existentes en la Biblioteca Nacional, que guardan ciertas similitudes con las obras del aragonés" 7 . Aquellos lienzos pintados por Goya reproducen la percepción del autor y su forma al plasmar unas imágenes de la Guerra. El pintor rompe con la composición clásica, porque el desorden se relaciona con el lenguaje de violencia, y utiliza los diferentes matices iconográficos y pictóricos para plasmarla.

Antes de cerrar este apartado, y porque sigue la línea comentada, es obligado mencionar otra significativa obra del pintor, que con diferentes títulos como Un gigante, El Coloso o El pánico, ha sido calificada por los especialistas, entre otros cosas, como enigmática y simbólica. Aunque no le han dado una fecha concreta se sabe que lo pintó antes de 1812, porque

\footnotetext{
6 «El pintor actúa en la serie como testigo, que denuncia reflexivamente los estragos, las atrocidades de la guerra a la que se parecía estar predestinado. Es posible que no tomase partido claro ni por el patriotismo español, ni por el imperialismo napoleónico. Simplemente denuncia mostrando su sinrazón y crueldad. No se trata de idealizar a los héroes, sino de mostrar la fiereza de la bestialidad humana en unas circunstancias determinadas» GARCiA MELERo, José Enrique: Arte Español de la llustración y del siglo xix. En torno a la imagen del pasado. Madrid, ediciones Encuentro, 1998, pág. 152.

7 García Melero, José Enrique: Pintura de los siglos XIx y X, Volumen I (De la Ilustración al Prerrafaelismo) Madrid, Universidad Nacional de Educación a Distancia, 2002, págs. 39-40.
} 
en el inventario de bienes de ese año sí aparece listado. Hay una serie de teorías establecidas por especialistas en el tema para explicar ese impresionante lienzo, posiblemente se relaciona con la idea del gigante, Napoleón, o con las agresiones y horrores de la Guerra. De cualquier forma, la escena es imponente y no, únicamente, por las dimensiones del coloso. Eso es lo impresionante porque Goya compone una escena, donde el caos y la estampida son más que verosímiles, una imagen real. Un óleo de 116 por 105 centímetros, que tiene un gran interés debido a la fuerza, al reflejo de aquel momento histórico, a la descomposición de las formas y a la utilización de una fuerza pictórica que dimensiona la escena.

\section{APROXIMACIÓN AL CONTEXTO HISTÓRICO DE GOYA EN LOS DESASTRES DE LA GUERRA}

Se trata de enmarcar los comienzos de la invasión napoleónica y sintetizar los hechos que desencadenan la guerra, para enlazar con la visión de Goya. El profesor Martínez de Velasco, en su estudio acerca de la Crisis dinástica, se refiere, entre otros factores a la ambición de Godoy y expone que el llamado proceso del Escorial no fue más que una acusación calumniosa contra el Príncipe de Asturias ${ }^{8}$, que indignó al pueblo. $Y$ también analiza la cuestión de que no existían motivos para creer que Napoleón Bonaparte pensase en algún momento en la anexión de España a Francia, puesto que como país satélite entraba en el nuevo orden europeo.

Señala que fueron tres las razones que llevaron al emperador a intervenir, por un motivo estratégico relacionado con la consolidación del bloqueo continental, porque la de los Borbones era una rama dinástica que podía desestabilizar su nueva legitimidad. "Por último, los Borbones españoles consideraron al emperador de los franceses como el árbitro supremo de sus disensiones internas, cada vez más numerosas y más públicas, y éste supo ampliar el arbitraje de los problemas familiares a la situación de todo el reino" " .

Por tanto, fue la situación provocada por el pueblo en contra de Godoy, Motín de Aranjuez, la que condujo al rey a abdicar en su hijo. A lo que seguiría el problema del pleito dinástico «La noticia de los acontecimientos de Aranjuez -caída de Godoy, renuncia de Carlos IV y elevación del Prín-

8 Martínez de Velasco, op. cit., pág. 24.

9 lbídem, pág. 26. 
cipe de Asturias-sorprendió tanto a Murat como a Napoleón... lo ocurrido destrozaba todos sus cálculos, porque suponía que la familia real no abandonaría la Península... Todo ello indujo a no dilatar la entrada en Madrid con sus tropas" ${ }^{10}$, que lo hicieron el 23 de marzo.

Días antes una carta de la ex-reina de Etruria, hermana de Fernando VII, le facilitaba la intervención en los asuntos de la familia real. La anulación del real decreto de abdicación abría un grave pleito entre padre e hijo. "Realmente el joven rey no podía considerarse seguro en el trono sin el apoyo y reconocimiento de Napoleón, dado que la familia real se encontraba dividida, las plazas fuertes en poder de los franceses y 40.000 hombres acantonados en Madrid "11. Además las órdenes eran detener a Fernando VII si rehusaba ir a Francia para la entrevista con el emperador.

El rey, que había dejado una Junta Suprema para gobernar en su nombre, cruzó la frontera el 20 de abril y diez días después Murat requirió a la Junta de Gobierno para la salida del infante don Francisco a Francia. Ese asunto provocó el ataque de un grupo de personas contra los franceses. «Desalojadas de la calle de Alcalá por la carga de la caballería. Las gentes se concentraron en la Puerta del Sol y en el Parque de Monteleón, cuya guarnición abrió el parque y sacó los cañones a la calle, donde se desarrolló una lucha tan violenta como desesperada en la que todos los medios utilizados eran buenos. Una vez reducidos los diferentes focos de resistencia, los franceses practicaron una represión totalmente incontrolada, de la que Goya dio un testimonio único en Los fusilamientos de la Moncloa... Los sucesos del 2 y 3 de mayo, conocidos en el resto de España por los partes oficiales publicados en la Gaceta de Madrid y por las relaciones de personas que abandonaron la corte posteriormente, crearon un clima de absoluta desconfianza ante las intenciones de los franceses en todo el territorio nacional» ${ }^{12}$. Las abdicaciones de Bayona significaron una ruptura con la línea borbónica y la imposición de un nuevo régimen, un nuevo rey, José I, y también la reacción, el levantamiento del pueblo contra la invasión, a lo que siguieron duras represiones y la brutalidad de la guerra.

Aquella Guerra de la Independencia (1808-14) contra los ejércitos napoleónicos se iniciaba, pues, con los levantamientos del 2 y 3 de mayo. Hechos que, según la historiografía, Goya presenció ${ }^{13} y$, como se ha ex-

lbídem, pág. 34

lbídem, pág. 37 .

Ibídem, págs. 40-41.

«Siempre se ha dicho que Goya fue espectador de las escenas representadas en sus cuadros, y que «La Carga de los mamelucos» en la puerta del Sol la contempló el dos de mayo 
puesto anteriormente, pintaría después de la Guerra. Aquella situación bélica de represión, confusión y horror sufrida por el pueblo, llevó al aragonés en 1810 a comenzar los dibujos preparatorios de las estampas de Los Desastres de la Guerra. Esa fecha la comparten los diferentes autores, que las han estudiado, pero en cuanto a la finalización se menciona 1820 , aunque es más repetida la de 1815 , cuando Goya había iniciado la siguiente serie, La Tauromaquia.

Lo realmente importante son los dibujos preparatorios que Goya realizó para los grabados, "la mayor parte en sanguina", que se conservan en el Museo del Prado. Sabemos que Goya regaló un álbum a su amigo Ceán Bermúdez (British Museum) con el titulo de Fatales consequencias de la sangrienta guerra en España con Buonaparte. Y otros caprichos enfáticos, en 85 estampas. Inventadas, dibuxadas y grabadas, por el pintor original D. Francisco de Goya y Lucientes. Dicho álbum tiene el extraordinario interés de recoger las leyendas a lápiz en cada estampa. Sin embargo, Goya no las publicó, posiblemente porque el lenguaje pictórico era muy crítico y, además, acabó la serie cuando la restauración en el trono de Fernando VII.

En cuanto a las planchas, la historiografía menciona, que quedaron en poder del hijo de Goya, Javier, cuando el 2 de mayo de 1824, a los 78 años, el pintor solicita al rey le permita trasladarse a Francia para tomar las aguas en el balneario de Plombières. Vive en Burdeos y su primera estancia se alarga hasta el mes de mayo de 1826. A su vuelta el rey le concede el sueldo y la jubilación y al mes siguiente se traslada de nuevo a Burdeos, donde (16-4-1828) muere.

Javier Goya las guardó hasta su muerte en 1854 y, dos años después, su nuevo propietario, Jaime Machén Casalins, las quiso vender al estado, pero no fue hasta 1862 cuando la Academia de Bellas Artes de San Fernando las adquirió. Un año después, con algunos retoques en los cobres, se publicaron, aunque no con el título que Goya le había dado en el álbum citado cuaderno de Ceán Bermúdez, pero sí se copiaron los títulos de cada una de las estampas. Editadas las ochenta primeras porque las dos últimas no fueron adquiridas por la Academia hasta el año 1870, y serían

desde el balcón de la casa de su hijo Javier en la calle de los Cofrades, que desembocaba en esta plaza. De ahí la poca profundidad de la escena al ser contemplada desde un estrecho callejón y desde un punto de vista alto. Ello se manifiesta, sobre todo, en el boceto (Col. Duque de Villahermosa, Madrid). Pero lo más posible es que Goya sintetiza en ambos lienzos sus visiones personales de distintos acontecimientos similares acaecidos durante la guerra. Estas vivencias se convierten en símbolos por acción de la pintura elaborada que transforma las impresiones en hechos inmutables y universales». Ibídem, pág. 40. 
impresas mucho después, en 1957. A la citada serie de planchas se han añadido, recientemente dos más.

\section{UNA VISUAL DE LO DESCRIPTIVO SIMBÓLICO EN LOS DESASTRES DE LA GUERRA}

Aquí se sigue la división dada por la historiografía para la serie, formada por ochenta y dos estampas ${ }^{14}$, en la que se señala la número uno, Tristes presentimientos de lo que ha de acontecer, como estampa introductoria. Las imágenes de la dos a la cuarenta y siete muestran el lenguaje expresivo de los horrores de la guerra. El siguiente grupo, de la cuarenta y ocho a la sesenta y cuatro expresan en escenas el hambre causado por la guerra. De la 65 a la 80 corresponden a los llamados caprichos enfáticos y cierran la serie las dos estampas que no se editaron en la primera publicación.

En la estampa introductoria del álbum, que tiene el significativo título Tristes presentimientos de lo que ha de acontecer, Goya utiliza una sencilla composición pictórica explicativa formada por una figura de rodillas y en actitud suplicante para mostrar la soledad e indefensión

\footnotetext{
14 Es realmente clarificador para entender el lenguaje singular del conjunto leer los títulos de cada una de las estampas, todavía tiene más interés, desde el punto de vista de las crueldades de la guerra el ver los dibujos de las estampas, no obstante, a continuación se adjunta una RELACIÓN con sus números: Tristes presentimientos de to que ha de acontecer (1). Con razón o sin ella (2). Lo mismo (3). Las mugeres dan valor (4). Y son fieras (5). Bien te se está/Goya (6). Que valorl (7). Siempre sucede (8). No quieren (9). Tampoco (10). Ni por esas (11). Para eso habeis nacido/Goya (12). Amarga presencia/Goya (13). Duro es el pasol (14). Y no hai remedio/Goya (15). Se aprovecha/Goya (16). No se conviene/Goya (17). Enterrar y callar/Goya (18). Ya no hay tiempo/Goya (19). Curarlos y á otra/Goya 1810 (20). Será lo mismo/Goya (dos veces) (21). Tanto y mas/Goya 1810 (22). Lo mismo en otras partes/Goya (dos veces) (23). Aún podrán servir/Goya (24). Tambien estos/Goya 1810 (25). No se puede mirar/Goya (26). Caridad/Goya 1810 (27). Populacho (28). Lo merecía (29). Estragos de la guerra (30). Fuerte cosa es! (31). Por qué? (32). Que hai que hacer más? (33). Por una navaja (34). No se puede saber por qué (35). Tampoco (36). Esto es peor (37). Bárbaros! (36). Grande hazaña! Con muertos! Goya (39). Algun partido saca (40). Escapan entre las llamas/ Goya (41). Todo va revuelto (42). Tambien esto (43). Yo lo vi/Goya (44). Y esto tambien/Goya (45). Esto es malo (46). Así sucedio (47). Cruel lástimal (48). Caridad de una muger (49). Madre infeliz! (50). Gracias á la almorta (51). No llega a tiempo (52). Espiro sin remedio (53). Clamores en verano (54). Lo peor es pedir/Goya (55). Al cementerio (56). Sanos y enfermos (57). No hay que dar voces (58). De qué sirve una taza? (59). No hay quien los socorra (60). Si son de otro linage (61). Las camias de la muerte (62). Muertos recogidos (63). Carretadas al cementerio (64). Qué alboroto es este? (65). Extraña devoción ! (66). Este no lo es menos (67). Que locural (68). Nada. Ello diré (69). No saben el camino (70). Contra el bien general (71). Las resultas (72). Gatesca pantomima (73). Esto es lo peorl (74). Farándula de charlatanes (75). El buitre carnívoro (76). Que se rompe la cuerda (77). Se defiende bien (78). Murió la Verdad (79). Si resucitarâ? (80). Flero mostruol (81). Esto es lo verdadero (82).
} 
del hombre relacionada con la realidad de la guerra que presentía. Esa realidad es la que crea las atroces imágenes que Goya recoge en escenas, donde el tema son los horrores de la contienda. Rompe con la concepción de lo heroico y muestra la cruda realidad de la guerra, la que sufre el pueblo, y como un reportero gráfico actual, no retrata a la persona sino el momento, la situación. Goya utiliza, lógicamente, los necesarios detalles iconográficos para presentar a los soldados franceses, a los guerrilleros españoles y a la gente del pueblo, e igualmente para expresar la dura realidad de las victimas de la guerra. Su sin sentido Goya lo expresa, por ejemplo, en la segunda estampa, que titula Con razón o sin ella, y en la tercera que enlaza con un más de Lo mismo.

Con la guerra afloran «los mas bajos instintos humanos» como la tortura, la violación y el asesinato. Por ejemplo, la tortura la escenifica el pintor en las estampas $31,32,33$, en la primera recurre a la exclamación Fuerte cosa es!, y, en las siguientes, a las preguntas Por qué? Y Que hai que hacer más? son claramente demostrativas. Como la 9, 10, 11 y 13 , donde muestra otra lacra, la violación, con un lenguaje propio, No quieren, Tampoco, Ni por esas, para definirla también como Amarga presencia. A lo que se añade otro horror el del asesinato, como puede verse en $(15,26,46)$ Y no hai remedio, No se puede mirar, Esto es malo, y a ese duro enfoque se añaden escenas mucho más duras con empalados y mutilados en Esto es peor (37) y Grande hazaña! Con muertos! (39).

Si estas escenas revelan la tremenda dureza de la guerra las que ahora se comentan $(16,18,22,23,27)$-Se aprovecha, Enterrar y callar, Tanto y mas, Lo mismo en otras partes, Caridad -, muestran montones de cadáveres. Ese ambiente asfixiante de gran destrucción provoca el vómito (12), Goya en el título afirma Para eso habeis nacido, no hay pregunta.

Como ilustrado, Goya era muy critico y lo mismo que en la serie los $\mathrm{Ca}$ prichos trata de forma bastante dura al clero y aunque se ocupa $(6,20,24$, 25) de su mirada se define en los títulos Bien se te está. Curarlos y á otra. Aún podrán servir, Tambien estos. Expresa de forma atrevida las imágenes sombrías y pesimistas.

A partir de la estampa 48 , Goya dirige su mirada a otro gran problema el Hambre y sus consecuencias, de las que el pintor tomó sus apuntes en las calles de Madrid. Sabemos que en el Antiguo Régimen las terribles hambrunas se repetían pero a la sufrida en los años 1811-1812 se añadía la escasez determinada por la guerra. También de forma anónima, el pintor dibuja hondas situaciones de mendicidad $(48,49,51)$, 
Cruel lástima!, Caridad de una muger, Gracias á la almorta, y dramáticas escenas $(50,51,53,58,60)$, Madre infeliz!, Gracias á la almorta, Espiro sin remedio, No hay que dar voces, No hay quien los socorra, donde los cadáveres están en la calle, esperando ser llevados Al cementerio (56), Muertos recogidos (63), Carretadas al cementerio (64), otro de los graves problemas por el escaso número de tales recintos fuera de las ciudades ${ }^{15}$.

Goya critica la prepotencia de otro de los pilares de la sociedad estamental la de los poderosos frente al pueblo en Espiro sin remedio (53) Clamores en verano (54), porque como explica Goya Si son de otro linage (61). Sin embargo, los especialistas del tema con los llamados 16 caprichos enfáticos mencionan la dificultad en interpretar la idea que Goya pretendía expresar. No obstante, las estampas 66, 67, 68 las interpretan en un «sentido anticlerical, de critica del culto a las imágenes y reliquias, aunque no hay que excluir otros significados". Extraña devoción! (66) Este no lo es menos (67) Que locural (68).

Mientras que la número $69 \mathrm{Nada}$. Ello dirá podía haber sido pensada por el pintor para cerrar la serie de los Desastres de la guerra con una escena simbólica, al mismo tiempo que expresa la inexistencia, la negación de la vida, un esqueleto deja la tumba para recalcar y constatar que quiere mostrar con el papel en la mano la Nada, para qué la idea de "decir» de expresar de existir si, cuando vuelve Fernando VII se reestablece el sistema anterior, la restauración, por lo que de Nada le vale al pueblo su entrega, sufrimiento, porque ha sido una quimera, un simulacro, una apariencia, nada, la negación al cambio.

Esa línea enlaza con la imagen que parecen expresar las estampas de la 70 a la 79 , donde Goya recurre a la imagen, en teoría menos cruenta de

\footnotetext{
15 «La construcción de cementerios fue otro de los propósitos del Ayuntamiento bonapartista. Las abundantes muertes que la guerra producía tuvieron que hacer, sin duda, más evidente la necesidad de construir estos recintos, ya que las bóvedas de las iglesias eran reducidas para hacer frente al creciente número de enterramientos. El 4 de Marzo de 1809 un decreto prohíbe el enterramiento en las iglesias pasar mejorar la salud pública y se manda construir en la Villa tres cementerios, uno en el camino de Extremadura, otro en el camino viejo de Leganés, y un tercero en el camino de Alcalá, pasada la tapia del Buen Retiro. Mientras estos cementerios se construyeran se enterraría en el ya existente. Nadie estaba eximido de cumplir este decreto cualquiera que fuera su condición. Esta no era una práctica nueva, el 3 de Abril de 1787, Carlos III en una Real Cédula había mandado restablecer el uso de cementerios... En la época de José I se concluyeron los dos cementerios generales en las afueras de la Puerta de San Bernardo, y de Toledo, titulándose del Norte y del Sur», en ANTIGüEdAD DEL CASTILLo OLIVARES, M.- Dolores: José Bonaparte y el Patrimonio artístico de Madrid de los conventos madrileños. Tesis Doctoral 42/87. Madrid, editorial de la Universidad Complutense de Madrid. Servicio de Reprografía, 1987, pág. 169.
} 
la guerra, pero que marcha paralela a la misma y se centra en el enfrentamiento ideológico de los partidarios de la Constitución, los liberales y los partidarios del régimen absolutista, que es el que se implanta. No saben el camino (70) Utiliza la imagen de animales en Las resultas (72) como vampiros, en la Gatesca pantomima (73) gatos, burros en Esto es lo peor! (74) o seres monstruosos en las estampas Contra el bien general (71) Farándula de charlatanes (75), El buitre carnívoro (76) Murió la Verdad (79) en su relación con la muerte de las libertades y la Constitución, pero se pregunta Si resucitará? (80). Con esa dualidad de contrarios titula la estampa 81 , Fiero monstruo! y la 82 con Esto es lo verdadero.

En síntesis, lo que se ha pretendido es, a partir de un estudio analítico, releer algunas de las páginas que el gran pintor aragonés, Francisco de Goya y Lucientes, escribió en un determinado y crítico momento para el pueblo español, el de la Guerra de la Independencia. Con este acercamiento se constata las realidades que rodean y determinan un hecho histórico de consecuencias tan graves como la guerra y que el pintor sintió y plasmó en sus obras, donde, además de fuente documental, muestra en toda su crudeza la estética formal y pictórica de todos aquellos factores que determinan el llamado Antiguo Régimen. 